\title{
BEACH EROSION COUNTERMEASURE USING NEW ARTIFICIAL REEF BLOCKS
}

\author{
Kyuhan Kim ${ }^{1}$, Sungwon Shin ${ }^{1}$, Chongkun Pyun ${ }^{2}$, Hyundong Kim ${ }^{3}$, and Nobuhisa Kobayashi ${ }^{4}$ \\ Two-dimensional and three-dimensional laboratory experiments were conducted to investigate not only the flow \\ mechanism near the submerged breakwater but the performance of two newly developed eco-friendly artificial reef \\ blocks. The results of two-dimensional experiments proved that new artificial blocks (EREEB) showed a better \\ performance than TTP in terms of wave attenuation due to wave breaking turbulence near the crest of the structure. \\ Three-dimensional experiments convinced that installing another type of new artificial block (WERF) in between \\ submerged breakwater reduced the return flow velocity more than 50\% compared with the gap between the \\ breakwaters is empty. Therefore, these two types of newly developed artificial reef block can contribute the counter \\ measure of beach erosion and habitat of sea lives.
}

Keywords: artificial reef block, submerged breakwater, beach erosion, return flow, and laboratory experiments.

\section{INTRODUCTION}

Recently the construction of submerged breakwater has been increasing in the coastal area. Submerged breakwater is widely used to reduce wave energy on beaches, seawalls, dikes, coastal roads and residential areas of the coasts. It is because submerged breakwater is more effective than detached emerged breakwater in the aspects of ocean view and water circulation. It also has more eco-friendly impacts on the coastal environment and ecology.

As a beach erosion countermeasure, the efficiency of submerged breakwater can be maximized at steep slope beach regions accompanying high swells by using beach nourishment.

Beach nourishment is considered to be one of the most eco-friendly erosion countermeasures so that it has been the most preferred and widely used mitigation in the field. However, in the case of steep beach, its short sustainability is inevitable.

According to the previous studies, minimum 5 years of nourished sand sustainment is required to meet the economical feasibility. Nevertheless, there is much loss of nourished sand in steep-sloped beach regions. Especially in Korea and Japan where river is the main source of sand for both countries, there are steep river and beach slopes that the nourished sand disappears easily.

Perched beach method, adding nourishment sand behind the submerged breakwater, is developed to redeem the weakness of those geographical problems. Many studies were implemented with this method and the results were successful.

And with its efficiency and effectiveness, submerged breakwater has become a common beach erosion countermeasure, especially in steep-sloped beach regions with high wave energy.

However, secondary problems arose in the use of perched beach countermeasure. Submerged breakwater is designed to build with gaps in the consideration of water circulation. And those gaps create return flow which results the secondary beach erosion problems. In this study, controlling and reducing the return flow is studied and more effective eco-friendly submerged breakwater blocks are introduced.

\section{NEW ARTIFICIAL REEF BLOCKS FOR SUBMERGED BREAKWATER}

Figure 1 shows the new eco-friendly artificial block. Each reef block is respectively combined to perform the function of artificial reef. The figure shows the opening gap made inside of reef and the crest of reef that is united as a jagged form. Transmitted wave dissipation occurs by the unevenly jagged formation and complicated opening gap inside of reef. Also, with ascidians growing inside of the gaps, the block functions as a fishing bank which helps the ocean ecology. A new eco friendly reef block is composed of 3 different blocks as shown in the figure. The combination of each type of block makes one perfect submerged artificial reef. When type 1 and type 2 interlock each other, type 3 will support in the bottom as a crosspiece to fit the interlocked blocks as a whole in the final stage

\footnotetext{
${ }^{1}$ Waterfront and Coastal Research Center, Kwandong University, Gangneung, Gangwond-do,201-701, South Korea

${ }^{2}$ Civil Engineering, Myongji University, Yongin, Gyeonggi-do,449-728, South Korea

${ }^{3}$ Civil and Environmental Engineering, UCLA, Los Angeles, CA, U.S.A.

${ }^{4}$ Civil and Environmental Engineering, University of Delaware, Newark, DE, 19716, U.S.A.
} 


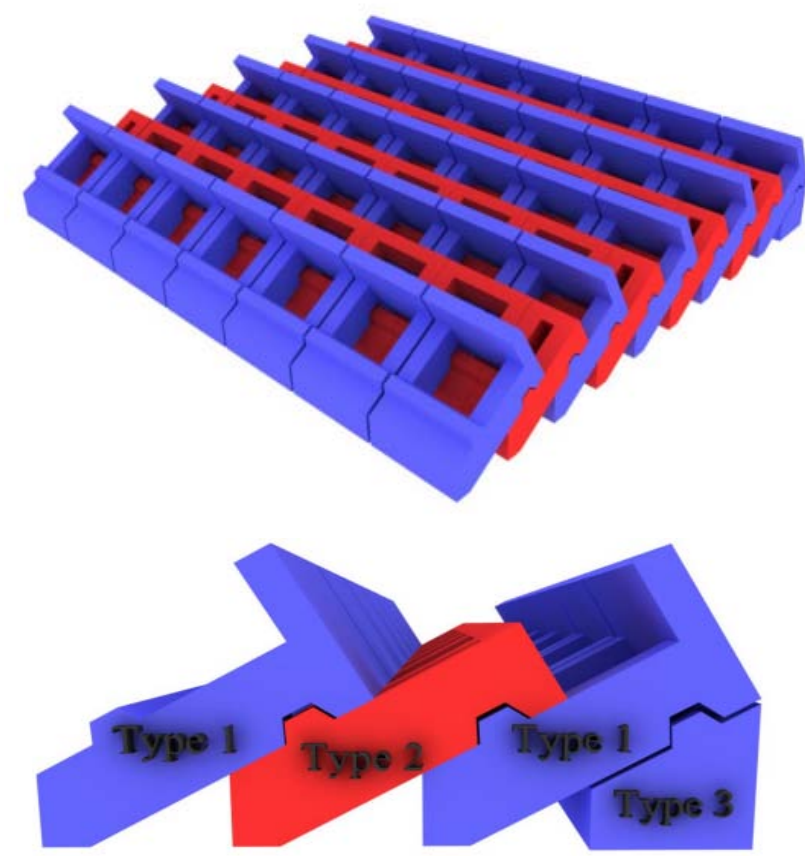

Figure 1. Design of new artificial block, EREEB (Eco REEf Block). Upper panel shows the combination of three types of block piece. Lower panel is magnified picture of interlocking formation of type 1, 2 and 3.

General view installed in the submerged breakwaters is shown in Figure 2. As shown in the figure, submerged breakwaters are generally built with gaps considering water circulation. However, the wave setup landward of submerged breakwaters causes return flow through the gaps. This kind of return flow transports the nourished sand offshore through the gaps.

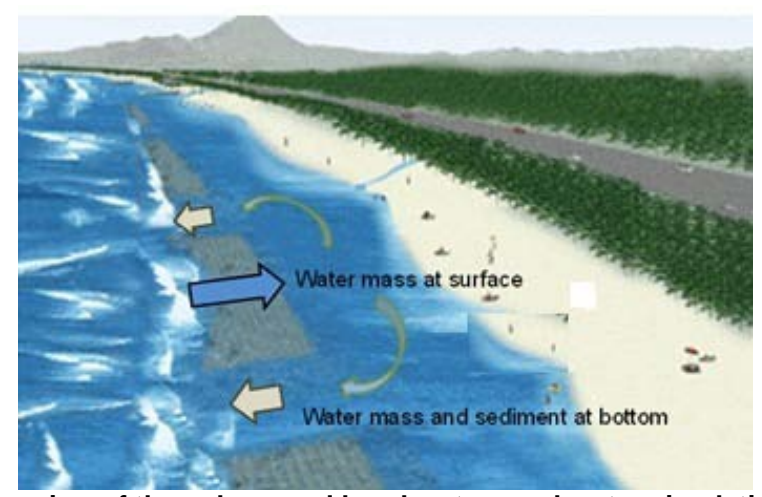

Figure 2. An overview of the submerged breakwaters and water circulation pattern.

Also, local scouring is produced in nearby surroundings of submerged breakwater due to return flow effects. Therefore, the velocity of return flow must be reduced in order to limit the offshore sand transport. Figure 3 demonstrates the new developed block which copes with the velocity of return flow. The block has two functions; exchanging water and reducing the velocity of return flow.
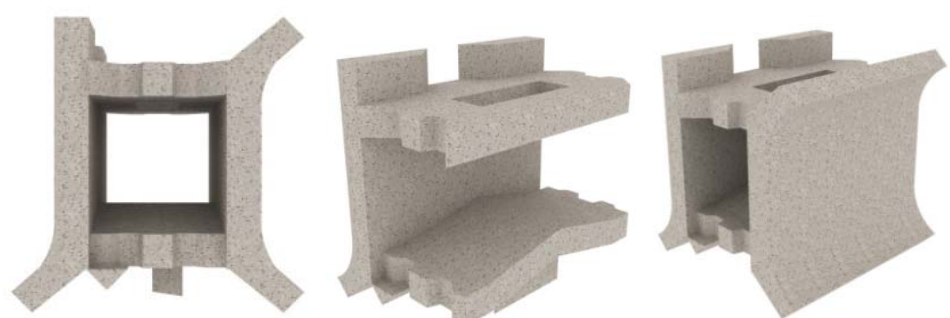

Figure 3. A Newly developed artificial block (WERF, Water Exchange and Return Flow reduction block) for reducing return flow velocity in the gap between the submerged breakwaters. 


\section{EXPERIMENTAL INVESTIGATION FOR THE PERFORMANCE OF NEW ARTIFICIAL BLOCKS.}

In order to investigate the performance of the newly developed artificial blocks, two-dimensional and three-dimensional hydraulic model tests were conducted.

At first, two-dimensional wave flume tests were conducted to investigate the capability of wave energy reduction. The new eco-friendly artificial reef blocks as a submerged breakwater were tested in two-dimensional glass walled wave flume with $30 \mathrm{~m}$ long, $1 \mathrm{~m}$ wide, and $1.5 \mathrm{~m}$ deep (Figure 4 ). The beach started with the slope of $1 / 10$ for $2 \mathrm{~m}$ distance and changed the slope with 1/30 until the flat section. The model of the submerged breakwater was installed the toe of the flat section. Capacitance type wave gages were used to measure wave heights for the analysis of wave reflection and transmission. The model was scaled down to 1/50 to fit the flume capacity.

The tests were conducted with changing parameters: 1,3 , and $5 \mathrm{~m}$ of wave heights $(\mathrm{H}), 5,7,9,11$ seconds of wave periods (T), 20,40, and $60 \mathrm{~m}$ of crest width (B), and 0.5 and $1 \mathrm{~m}$ of freeboard (R). All the scale mentioned above were already converted to prototype scale. The experiments were conducted with these conditions to investigate not only the characteristics of wave reflection and transmission but the performance of blocks. The detailed results are in the previous study (Kim, et al., 2011)

Figure 5 shows the photograph of the experimental setup and the snap shot of the experiment. This snap shot proves that waves are broken on the crest of reef blocks and generated vortices. These mechanisms reduce wave energy and prevent beach erosion behind the submerged breakwater. Also the tests with same conditions were conducted using TTP to compare its performance with new ecofriendly artificial reef blocks.
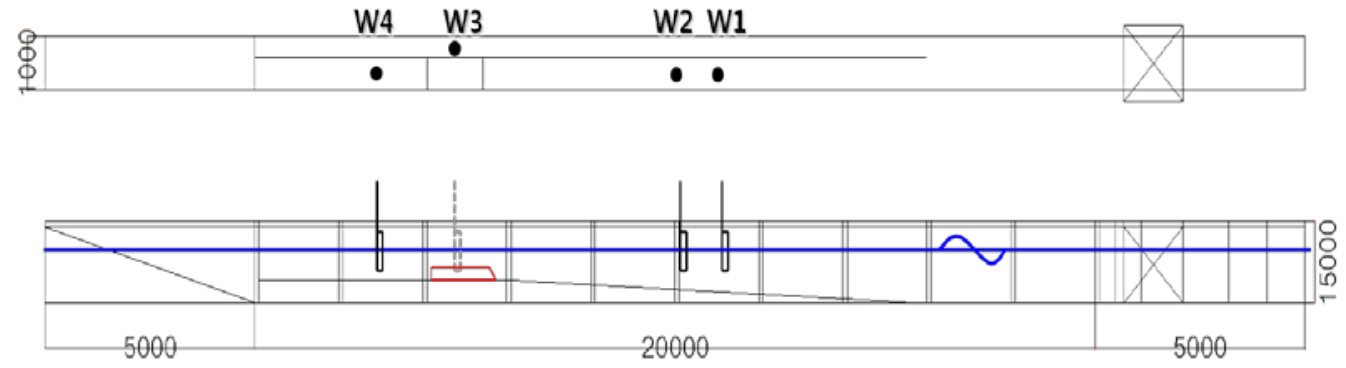

Figure 4. A definition sketch of the setup and instrumentation for two-dimensional experiment.

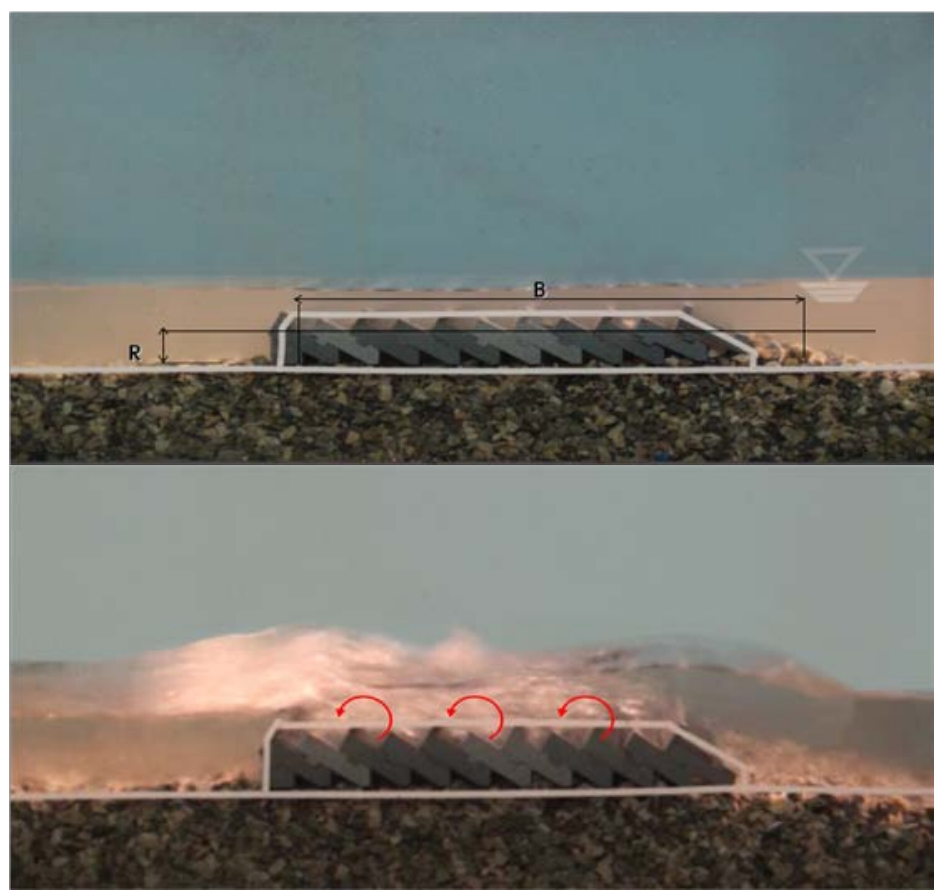

Figure 5. Experimental setup (upper panel, $B=20 \mathrm{~m}, \mathrm{R}=1.0 \mathrm{~m}$ in prototype scale). Lower panel shows the vortices generated by wave breaking. 


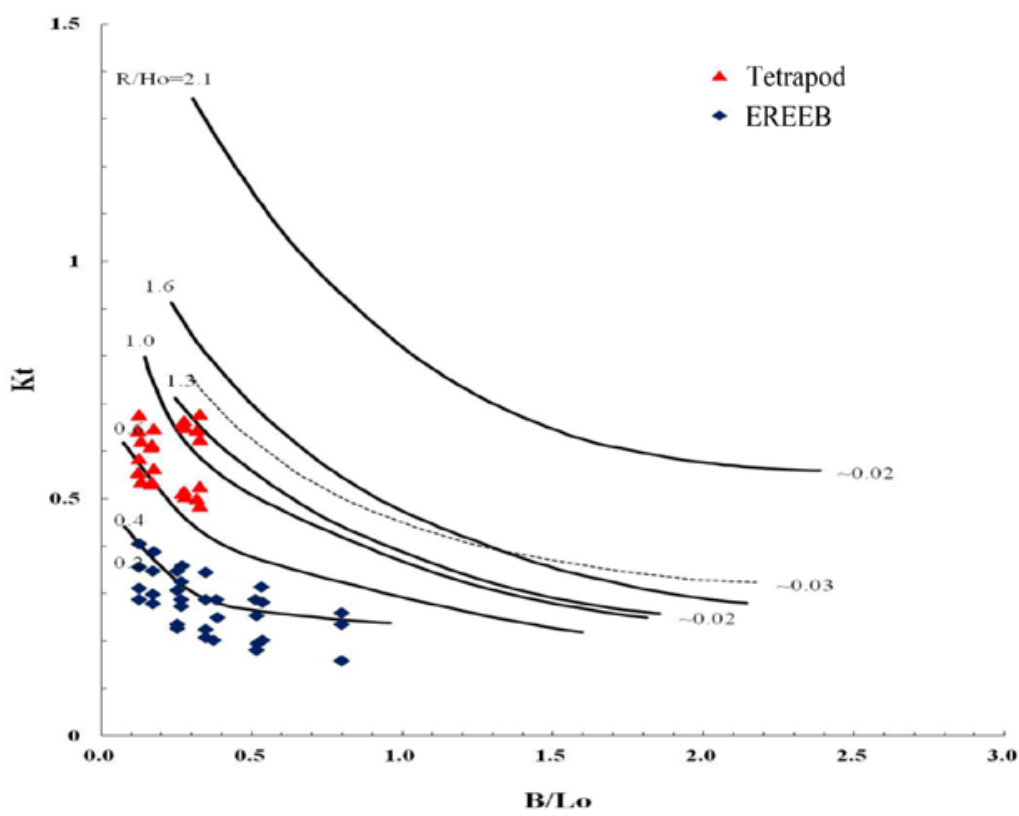

Figure 6. Transmission coefficients as a function of characteristic length of submerged breakwater. Diamond symbols (blue) are the results of eco-friendly artificial reef block (EREEB). Triangles are the results of TTP.

Figure 6 shows that the performances of the new eco-friendly artificial reef (EREEB) in terms of normalized runup were compared with those of TTP. We added the results of EREEB and TTP in the curve published by “A design manual of artificial reef (2004)” in Japan. The figure proves that the EREEB has a better performance than TTP in terms of wave transmission and runup on the beach.

Three-dimensional hydraulic model tests were conducted to investigate return flow pattern through the gap between the submerged breakwaters. Two different setups of the experiment were performed in 3D wave basin with $27 \mathrm{~m}$ long, $37 \mathrm{~m}$ wide, and $1.5 \mathrm{~m}$ deep in 1/100 scale. The flow pattern was investigated for conventional configuration of rubble mound submerged breakwater. The other case was conducted using WERF installed in the gap and measured return flow velocities.

Figure 7 is the plan view of the two different experimental setups. The left figure shows the conventional installation of the submerged breakwater which allows return flow the gap. In the right figure, WERFs (green and red parts) were installed in the gap between the submerged breakwaters to reduce the return flow velocity while they allow the water exchange. Return flow velocities were estimated by tracking dark blue colored dye under the regular wave condition with different wave heights and periods.
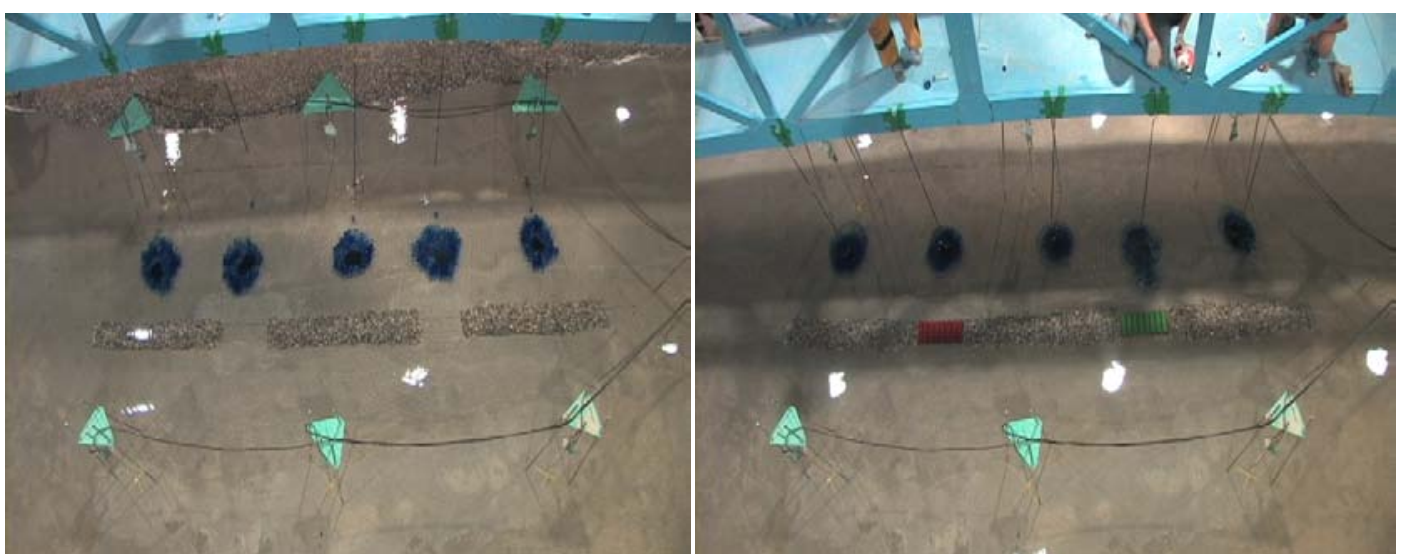

Figure 7. 3D experimental setup for flow pattern investigation through the gap. Dark blue colored dye was used to track the return flow. 
Figure 8 shows the horizontal return flow velocity under those two cases as a function of wave stiffness. This figure proves that, when the taps were filled with WERFs, the return flow velocities were reduced more that $50 \%$ compared with the gaps were empty.
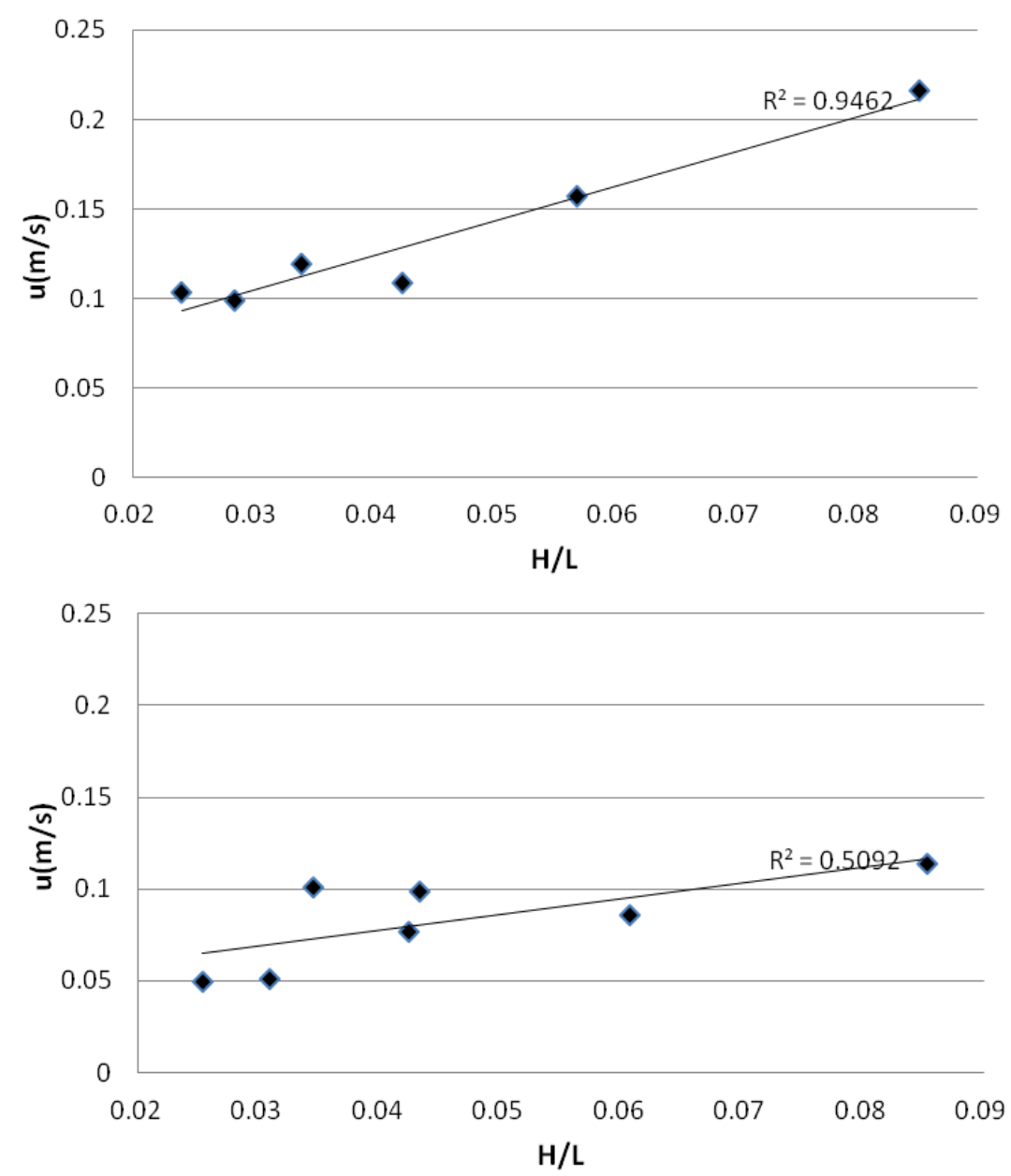

Figure 8 Horizontal return flow velocities as a function of wave stiffness. Upper panel is the case without WERF in the gap. Lower panel shows the result with WERF.

\section{CONCLUSION}

In this study, new eco-friendly submerged breakwater block is introduced and its effectiveness in hydraulic characteristic is evaluated with hydraulic model experiments.

Also, secondary problems of submerged breakwaters by means of beach erosion countermeasure are brought to attention. Among the secondary problems, return flow is studied in depth for complementary measures. With the consideration of water circulation involved with the gaps of submerged breakwaters, an ideal method of reducing the velocity of return flow and minimizing nourished sand wash-down to offshore is introduced.

In order to understand and prove the two problem using ERREB and WERF, two-dimensional and three-dimensional hydraulic model tests were conducted. Through you the experiments, the conclusions that we obtained are:

- EREEB showed a better performance than TTP in terms of wave attenuation in 2D experiments due to the turbulence. (similar capability to rubble mound breakwater)

- 3 D Experiment result shows that installing WERF in between submerged breakwater caused more than fifty percentage of velocity reduction in return flow.

In the future, velocity field and sediment transport pattern will be measured in 3D experiments. Also, EREEB and WERF will be tested in the specific site of the real coast where beach erosion is severe. 
Furthermore, a comparative study between numerical analysis on the hydrodynamic characteristics of WERF blocks employed in the gaps and its hydraulic model experiments is necessary. Also, close examination and accurate analysis throughout the studies will be essential.

\section{ACKNOWLEDGMENTS}

This work was supported by the Regional Innovation Center Program at Kwandong University of the Ministry of Knowledge Economy and a Manpower Development Program for Marine Energy by the Ministry of Land, Transport and Maritime Affairs (MLTM).

\section{REFERENCES}

A design manual of artificial reef. 2004. National association of coast in Japan (in Japanese),

Kim, K., S. Shin, W. Lim, Y. Moon, and C. Pyun. 2011. An Experimental Study on the Wave Control by Environment-Friendly Artificial Reef. Proceedings of the $6^{\text {th }}$ International Conference on Asian and Pacific Coasts, CD-Rom, Hong Kong, China. 